\title{
Template-based landmark and region mapping of bone
}

\author{
Jaeil Kim', Sang Gyo Seo ${ }^{2}$, Dong Yeon Lee ${ }^{2}$, Jinah Park ${ }^{1 *}$ \\ From 4th Congress of the International Foot and Ankle Biomechanics (i-FAB) Community \\ Busan, Korea. 8-11 April 2014
}

\section{Background}

The shape morphology using 3D surface models has been recently emerged for biomechanics research, such as the quantitative assessment of bone deformity with clinical factors [1] and the correlation analysis between bone shape and joint motion [2]. In the bone shape morphology, the morphological difference of the bones across subjects is quantified by the geometric measures, such as the curvature of the articular surface and the relative bone orientation in joints, defined with the anatomical landmarks and regions on the bone surface. However, the landmark and region determination on individual cases is a difficult and time-consuming task, because of the various size and shape of the bones and operator's errors.

In this paper, we propose an automated landmark and region mapping method based on a non-rigid template-toimage registration. The template model is a triangular mesh including the generic shape of the target. It also encodes the landmarks and regions as a subset of the points in the triangular mesh. For the landmark and region mapping to individual bones, the template model is nonrigidly deformed by a Laplacian deformation framework [3]. This framework derives the point transformation into the image boundary while minimizing the distortion of the point distribution in the template model. This behavior of the deformation framework helps to trace the positions of the anatomical landmarks and regions across subjects.

\section{Results}

For our experiment, the calcaneus template model was constructed from the manually segmented CT scans. We assigned 7 landmarks and the articular surface for the talus in the calcaneus model. We applied our method to the segmentations of three subjects having the different

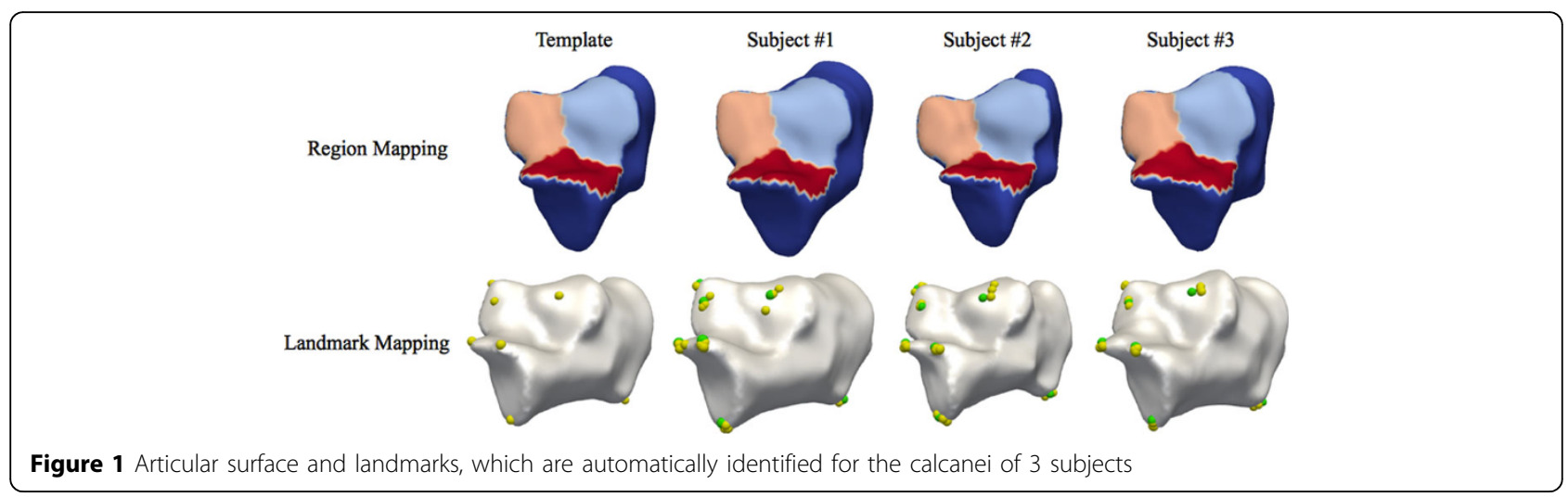

\footnotetext{
* Correspondence: jinahpark@kaist.ac.kr

${ }^{1}$ Department of Computer Science, Korea Advanced Institute of Science and

Technology, Daejeon, South Korea

Full list of author information is available at the end of the article
}

(c) 2014 Kim et al; licensee BioMed Central Ltd. This is an Open Access article distributed under the terms of the Creative Commons 
size calcanei. Figure 1 (top) shows the reconstructed models with the articular surfaces, which were automatically labeled, shown in different colors. The accuracy of the individual shape reconstruction was a volume overlap (complete overlap $=1.0$ ) of $0.981 \pm 0.009$ and a mean distance of $0.349 \pm 0.423 \mathrm{~mm}$ with respect to the segmentations. To validate the consistency of the automatic landmark determination, three blinded operators manually assigned the landmarks in the reconstructed models. Considering the inter-operator variations, the automatic landmarks (green) were consistent with the manual landmarks (yellow) in the template and individual models, as shows in Figure 1 (bottom). These results indicate that our method determines the accurate positions of the anatomical landmarks and regions while restoring the individual shape characteristics of bones. We plan to assess the robustness and accuracy of the automatic landmark and region mapping with larger datasets.

\section{Acknowledgement}

This research was supported by Basic Science Research Program through the National Research Foundation of Korea(NRF) funded by the Ministry of

Education, Science and Technology(No. 2011-0009761).

\section{Authors' details}

${ }^{1}$ Department of Computer Science, Korea Advanced Institute of Science and Technology, Daejeon, South Korea. ${ }^{2}$ Orthopedic Surgery, Seoul National

University Hospital, Seoul, South Korea.

Published: 8 April 2014

\section{References}

1. Neogi T, Bowes MA, Niu J, De Souza KM, Vincent GR, Goggins J, Zhang Y, Felson DT: Magnetic resonance imaging-based three-dimensional bone shape of the knee predicts onset of knee osteoarthritis: data from the osteoarthritis initiative. Arthritis Rheum 2013, 65:2048-2058.

2. Peeters K, Schreuer J, Burg F, Behets C, Van Bouwel S, Dereymaeker G, Sloten JV, Jonkers I: Alterated talar and navicular bone morphology is associated with pes planus deformity: A CT-scan study. J Orthop Res 2012, 31:282-287.

3. Kim J, Park J: Organ Shape Modeling Based on the Laplacian Deformation Framework for Surface-Based Morphometry Studies. J Comp Sci Eng 2012, 6:219-226.3.

doi:10.1186/1757-1146-7-S1-A42

Cite this article as: Kim et al:: Template-based landmark and region mapping of bone. Journal of Foot and Ankle Research 2014 7(Suppl 1):A42.

\section{Submit your next manuscript to BioMed Central} and take full advantage of:

- Convenient online submission

- Thorough peer review

- No space constraints or color figure charges

- Immediate publication on acceptance

- Inclusion in PubMed, CAS, Scopus and Google Scholar

- Research which is freely available for redistribution

Submit your manuscript at www.biomedcentral.com/submit
C Biomed Central 